\title{
Vaccine Coverage of Newly Introduced Vaccines and Factors Influencing among Children Less Than 23 Months in Laikipia North Subcounty
}

\author{
Donald Mogoi*, Eric M. Muchiri, Alfred M. Mutuma \\ School of Health Sciences, Meru University of Science and Technology, Nanyuki, Kenya \\ Email: ^Donmmogoi35@gmail.com
}

How to cite this paper: Mogoi, D., Muchiri, E.M. and Mutuma, A.M. (2020) Vaccine Coverage of Newly Introduced Vaccines and Factors Influencing among Children Less Than 23 Months in Laikipia North Subcounty. Open Journal of Preventive Medicine, 10, 9-43.

https://doi.org/10.4236/ojpm.2020.102002

Received: January 13, 2020

Accepted: January 31, 2020

Published: February 3, 2020

Copyright $\odot 2020$ by author(s) and Scientific Research Publishing Inc. This work is licensed under the Creative Commons Attribution International License (CC BY 4.0).

http://creativecommons.org/licenses/by/4.0/

\begin{abstract}
The epidemiology of vaccine preventable diseases has been modified by use and implementation of various vaccination programs in many countries. However, because of observed suboptimal vaccination rates, debate has emerged on the benefits of such vaccines worldwide. Maternal and childhood vaccinations have been evaluated and found extremely effective at preventing illness in pregnant women and new-borns despite low uptake of such vaccines in many areas. The objective of this study was to determine the Vaccination Coverage and factors that influence uptake of newly introduced vaccines among children aged less than 23 months in Laikipia North Sub-County. The study used multistage sampled parents and guardians of children below 23 months of age but residents of Laikipia North Sub-County within Laikipia County. Trained interviewers visited sampled households and administered a standardized pretested questionnaire. Mothers and guardians were interviewed and asked to show the interviewers Mother-Child Post Natal Booklets for the study enrolled children. Key informant questionnaires were also administered to Health facility staff. Data entry and analysis were performed using SPSS and Microsoft Excel. Chi-Square for Proportion and Student T-test were used to assess factors influencing uptake of vaccines in the sub-county. The study found that slightly above half (59\%) of the care givers indicated that their child had been vaccinated. Majority (61\%) of the care givers had their children given rotavirus vaccine while an equal number (61\%) had their children given Pneumococcal vaccine. $52 \%$ of the care givers indicated that their children were given IPV (Inactivated Polio Vaccine). 53\% of the children who were given rotavirus vaccine received the required 2 doses. Among social-cultural factors, the need for permission from mother-in-law $(p=0.003)$, belief that vaccination makes girls infertile $(\mathrm{p}=0.046)$ and belief that vaccination at a very young age can harm the child $(\mathrm{p}=0.021)$. Migration with
\end{abstract}


animals or nomadic lifestyle $(\mathrm{p}=0.033)$ and the need for permission from my husband to have Child Immunized $(\mathrm{p}=0.038$ ) were significantly related to uptake of vaccination among the care givers. Occupation of the care giver $(\mathrm{p}$ $=0.044)$, the breadwinner in the family $(p=0.025)$ and the means of transport used to go to the facility $(\mathrm{p}=0.007)$ and average household income $(\mathrm{p}=$ 0.033) were also significantly related to uptake of vaccination. None of the health system factors under investigation was found to significantly relate to uptake of vaccination. The study finding indicates that low uptake of vaccination was due to social cultural and social economic factors and recommends that Health education campaigns on the need of vaccination should target all members of the population. It further recommends that poverty eradication measures should be stepped up in the study area.

\section{Keywords}

Infant, Vaccine, Vaccination Coverage, Factor

\section{Introduction}

\subsection{Background to the Study}

Vaccination is a lifesaving and cost-effective medical intervention which reduces childhood morbidity and mortality from diseases. Globally, there are over 30 million children who are not routinely vaccinated every year and approximately 1.5 million children less than five years of age die each year from vaccine preventable diseases namely measles, Rota Virus Diarrhoea, Whooping cough (pertussis), Hemophilus influenza type B (HIB) and Tetanus [1].

Over the past two decades, tremendous progress has been made in halving worldwide maternal and child deaths, supported by the drive to meet Millennium Development Goals (MDGs) which ended in 2015. One of the targets of UN Sustainable Development Goals (SDGs) aims to continue this momentum by reducing the global maternal mortality ratio to less than 70 per 100,000 live births [2].

Kenya has made tremendous progress in the provision of vaccines; the KDHS 2014 puts the country's fully immunized child rate at 79\%, this falls below the World Health Organization recommended rate of over $80 \%$. However, great disparities exist among counties and within counties in terms of coverages. Arid and Semi-Arid parts of Kenya that are greatly inhabited by pastoralists have always performed poorly while settled communities generally perform well [1]. Laikipia County's coverage in the same survey was at $71 \%$ (37). However, within the same county, Laikipia North Sub-County that is Arid has always had low immunization coverages.

The epidemiology of vaccine preventable diseases has been modified by the development and implementation of vaccination programs, i.e., measles, mumps, rubella, and hepatitis B exhibit a decreasing trend of morbidity, but suboptimal 
vaccination rates constitute an important component of the health care debate worldwide [3]. Several socioeconomic factors and structural barriers have been incriminated for low immunization rates. Social determinants such as age of parents, low level of parental education, birth order of the child, financial barriers such as low family income, lack of health insurance and gaps in the relevant infrastructures such as lack of periodic primary health care access, or decreased availability of health care facilities, have been found to be associated with low immunization rates, in various geographically confined areas, without generalizable results [3].

The role of the parents' perceptions regarding the difficulty to access health services, health beliefs and attitudes toward childhood vaccination, is a controversial issue, Kiros et al. identified these as risk factors for decreased vaccination coverage, whereas others suggest that socioeconomic factors play a more important role, and a recent study proved that parents' beliefs may simply reflect their socio-demographic characteristics imposing the latter of principal, undisputable importance [4].

In Kenya, one out of 9 children dies annually from vaccine prevent diseases before the 5 th birthday. It has been noted that by expanding routine vaccination and increasing coverage, most of these lives could be saved. The WHO global target of $90 \%$ immunization coverage by 2010 was not achieved, though collaborative efforts to support the initiative were continued and maintained [5].

To reduce morbidity, mortality and disability due to vaccine preventable diseases, WHO, via the Government of Kenya, recommended eight different vaccine antigens in 4 vaccine formulations, free of charge for all vaccinees through the Division of Vaccine and Immunization (DVI). The targeted vaccines preventable diseases and the WHO adapted immunization schedules are: Tuberculosis vaccine (administered at birth), Poliomyelitis (at birth, 6 weeks, 10 weeks, and 14 weeks), Diphtheria, Pertussis, Tetanus, Hepatitis B and Haemophilus type b (at 6 weeks, 10 weeks and 14 weeks) and Measles at 9 months [6].

However, Kenya faces numerous deaths attributable to streptococcus pneumoniae, diarrhea due to Rota virus. These conditions in addition to measles, mumps and Rubella epidemics and the re-emergence of wild polio virus needed an introduction of new vaccines to help reduce mortality and morbidity from these vaccine preventable diseases.

The pace of new vaccine introductions in low- and middle-income countries has been accelerating in the past decade and will continue. This has led to increased attention to their broader effects, with the possibility that they may either stress or strengthen health systems in these countries [7]. Since the year 2010, Kenya through the Division of Vaccines and Immunization has introduced 4 new vaccines into the routine immunization schedule in the country. The 4 new vaccines are in addition to 4 others that were already in the schedule. The new vaccines that Kenya has so far introduced are pneumococcal vaccine (PCV 10 ) in 2010, Measles $2^{\text {nd }}$ dose in 2013; Rota virus vaccine in 2014 and inactivated 
polio vaccine in 2015. There are plans to introduce more new vaccines into the routine schedule in future.

Kenya adopted a new governance system in 2013. This was in order to satisfy the requirements of the constitution 2010 that introduced devolution as a system of governance and resource distribution within the country. Health and by extension vaccination services were also devolved.

While the Impact of newly introduced vaccine has been previously studied in Kenya with a lot of informative findings, the research dwelt on the impact of introducing a single vaccine and overall looked at Kenya as a country. Unfortunately, the study did not consider the effects that the new vaccines can have on a health system that is run by a devolved government. Previous research has also typically focused either on the impact of vaccination campaigns on the routine vaccination service, or the impact of new vaccine introduction on specific elements of the health system, such as cold chain, logistics and supply or coverage.

EPI is traditionally and relatively a vertical programme, although routine vaccination is arguably more integrated than vaccination campaigns. Research on the health system impact of other vertical health programmes, including vaccination campaigns; has identified both positive and negative effects. It has also been noted that these impacts varied depending on the strength of the health system. Despite all these studies, vaccination rate by vaccines is still low. The need for a survey in the distinctly diverse cultural factors of the Maasai and Samburu in Laikipia North in Laikipia County in Kenya is imperative. This study aims at establishing factors Associated with uptake of new vaccines among children aged less than one year in Laikipia North sub-County of Laikipia County.

\subsection{Research Questions}

What was the vaccination coverage for the newly introduced vaccines in Laikipia North Sub County?

What were the Social Cultural and Economic factors influencing uptake of newly introduced vaccines among children aged less than 23 months in Laikipia North Sub County?

What were the Health facility and Operational factors influencing the uptake of newly introduced vaccines among children aged less than 23 months in Laikipia North Sub County?

\subsection{Purpose of the Study}

\subsubsection{Main Objective}

To determine the Vaccination Coverage and Factors Influencing the uptake of newly introduced vaccines among children aged less than 23 Months in Laikipia North Sub County Laikipia County.

\subsubsection{Specific Objectives}

To determine the vaccine coverage for various vaccine antigens in Laikipia 
North Sub-County.

To determine the Social-Cultural and Economic Factors Influencing the uptake of newly introduced vaccines among children aged less than one year in Laikipia North Sub-County.

To determine the Health Facility and Operational Factors Influencing the uptake of newly introduced vaccines among children aged less than one year in Laikipia North Sub-County.

\section{Materials and Methods}

The study was a cross-sectional study among care givers of Children aged less than 23 months who received vaccines from health facilities in Laikipia North Sub County. Data collection was through pre-tested structured questionnaire, observational check lists.

The primary study population was Care givers of Children aged 0 to 23 months who were residents of Laikipia North Sub-County.

Facility Health workers also participated as Key informants.

According to a Kenya National Bureau Statistics (KNBS) and the Kenya Census of 2009 estimated the population of Laikipia North to be 72,424 people, out of children aged 0 to 23 months are estimated to be 5506 children. This formed the target population that is also eligible for Immunization. However, sampling was done in order to determine the exact study population.

\subsection{Study Variables}

INDEPENDENT VARIABLES

DEPENDENT VARIABLES

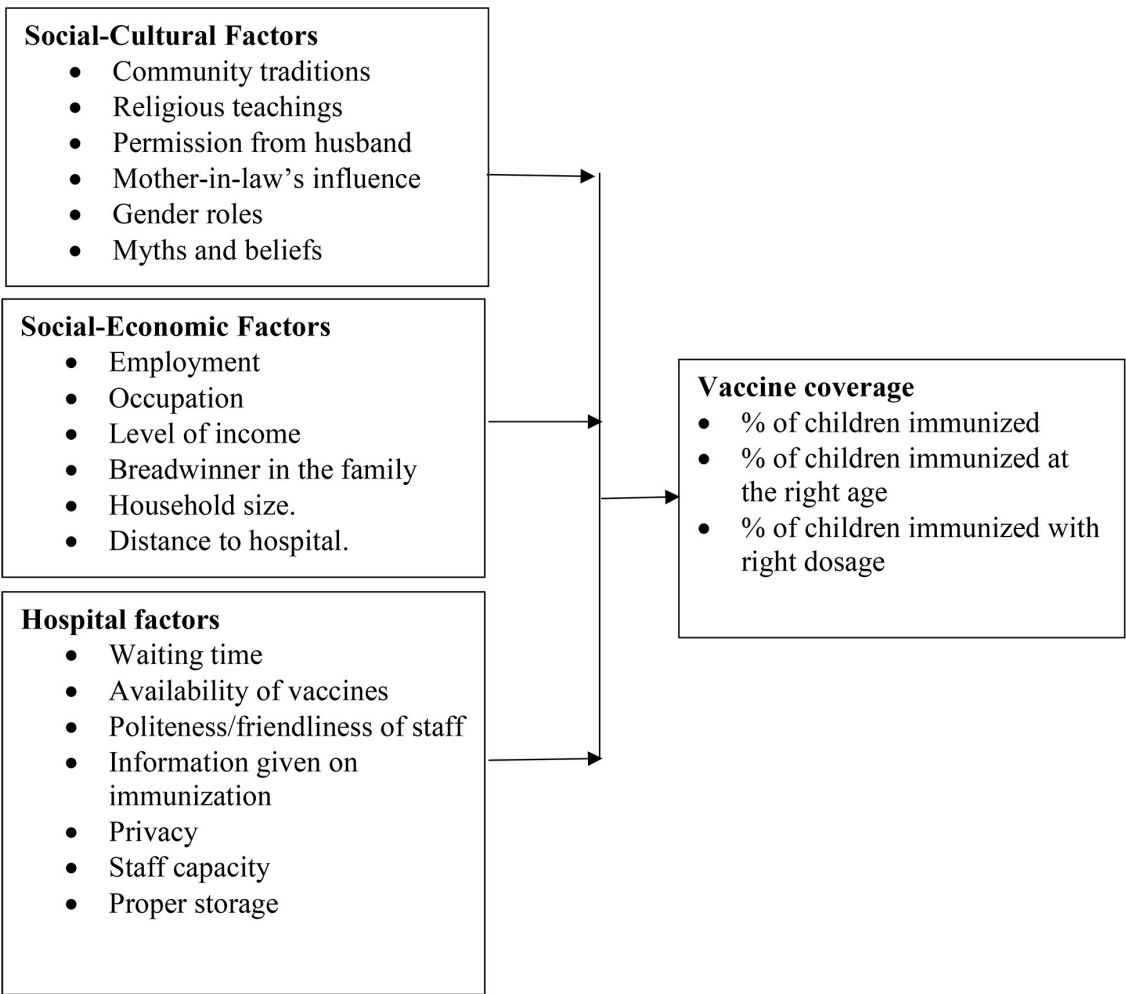




\subsection{Sampling Techniques and Sample Size}

\subsubsection{Sampling Design}

The sampling frame comprised of all children aged 0 months to 23 Months and living in Laikipia North Sub-County.

First, Laikipia North Sub-County was purposively selected for the study.

Proportionally allocated stratified technique was utilized to obtain the study sample.

All Sub locations in Laikipia north Sub County formed the clusters; each cluster contributed a sample population that was proportional to its population proportion for the sub-county.

Within each cluster, a random sample of all children aged between 0 and 23 months was taken in order to arrive at the study sample per cluster. The cluster samples were then pooled in order to arrive at the final sample population for the study.

Assistant Chiefs maintain a register of all births and deaths in their sub locations. This register formed the basis of selection of the caregivers to be visited. Each homestead that had a birth in the last 2 years was selected and accorded a number, this was written down, folded and placed in a cistern and mixed up. Interviewers randomly and blindly selected the folded pieces of paper from the cistern, equal to the sample size per sub location. The selected homesteads were then visited by the interviewers.

\subsubsection{Sample Size Determination}

The desired sample size was determined using the following Fisher et al. 1991 formulae;

$$
n=\frac{z^{2} p q}{d}
$$

where:

$$
n=\text { the desired sample size. }
$$

$Z=$ the standard normal deviate, set at 1.96 , which corresponds to $95 \%$ confidence level.

$P=$ probability of being immunized in Laikipia which is 0.71 .

$q=1.0-\mathrm{p}$.

$d=$ degree of accuracy desired, here set at 0.05 corresponding to the 1.96 $\mathrm{z}$-statistics used in the numerator.

In substitution,

$$
n=\frac{1.96^{2} \times 0.71(1-0.71)}{0.05^{2}}=316
$$

$5 \%$ was added to the sample size to take care of non-responsive participants. This added a total of 16 children to the sample, thus making the total sample size to be 332 (Table 1).

Laikipia North sub-county has 26 health facilities with 69 health workers dis- 
tributed as shown below (Table 2). All the health facilities formed the study sample for purposes of key informant interviews. Each health facility in charge formed the study population for the key informant interviews on health facility factors.

Table 1. Proportionate distribution of samples.

\begin{tabular}{|c|c|c|c|c|c|c|}
\hline LOCATION & $\begin{array}{c}\text { SUB } \\
\text { LOCATION }\end{array}$ & FACILITY & 2016 & $\begin{array}{l}\text { Children } 0 \\
\text { to } 23 \text { months }\end{array}$ & $\begin{array}{c}\% \\
\text { proportion }\end{array}$ & Sample \\
\hline Magandi & Magandi & & 3943 & 197 & 4.0 & 13 \\
\hline \multirow{2}{*}{ Mumunyot } & Mumunyot & & 2543 & 127 & 2.6 & 9 \\
\hline & Seek & & 1836 & 92 & 1.9 & 6 \\
\hline \multirow{2}{*}{ Ilingwesi } & Sangaa & & 1893 & 95 & 1.9 & 6 \\
\hline & Ngarendare & Ngaredare & 1666 & 83 & 1.7 & 6 \\
\hline \multirow{2}{*}{ Makurian } & Makurian & & 1592 & 80 & 1.6 & 5 \\
\hline & Arjijo & Arjijo & 2279 & 114 & 2.3 & 8 \\
\hline Mukogondo & Kurikuri & & 4103 & 205 & 4.2 & 14 \\
\hline Iligiri & Tura & & 3911 & 196 & 4.0 & 13 \\
\hline Sieku & Sieku & & 2199 & 110 & 2.2 & 7 \\
\hline \multirow{2}{*}{ Ilmotiok } & Ilmotiok & & 4139 & 207 & 4.2 & 14 \\
\hline & Mpalla & Mpalla & 1953 & 98 & 2.0 & 7 \\
\hline Ilipolei & Ilipolei & Ilipolei & 4533 & 227 & 4.6 & 15 \\
\hline \multirow{2}{*}{ Oloibosoit } & Ewaso & Ewaso & 3513 & 176 & 3.6 & 12 \\
\hline & Kirimon & Kirimon & 6675 & 334 & 6.8 & 22 \\
\hline \multirow{3}{*}{ Ethi } & Ethi & Ethi & 1820 & 91 & 1.8 & 6 \\
\hline & Chumvi & Chumvi & 4715 & 236 & 4.8 & 16 \\
\hline & Ngenia & Ngenia & 7800 & 390 & 7.9 & 26 \\
\hline \multirow{3}{*}{ Naibor } & Naibor & & 2903 & 145 & 2.9 & 10 \\
\hline & Mukima & Muramati & 2467 & 123 & 2.5 & 8 \\
\hline & Kimagandura & & 2657 & 133 & 2.7 & 9 \\
\hline \multirow{2}{*}{ Segera } & Segera & Segera & 5112 & 256 & 5.2 & 17 \\
\hline & NgareNgiro & & 2659 & 133 & 2.7 & 9 \\
\hline Impalla & Rugutu & & 3171 & 159 & 3.2 & 11 \\
\hline Marura & Marura & Marura & 8840 & 442 & 8.9 & 30 \\
\hline Lonyiek & Lonyiek & Lonyek & 3584 & 179 & 3.6 & 12 \\
\hline \multirow{3}{*}{ Sosian } & Kariwo & & 1859 & 93 & 1.9 & 6 \\
\hline & Sosian & & 2580 & 129 & 2.6 & 9 \\
\hline & Maundumeri & & 5817 & 291 & 5.9 & 20 \\
\hline \multicolumn{2}{|c|}{ TOTALS } & & 98818 & 4941 & 100 & 332 \\
\hline
\end{tabular}

SOURCE: County government of Laikipia. 
Table 2. Number and category of health facilities in Laikipia North Sub-County.

\begin{tabular}{ccc}
\hline FACILITY TYPE & NUMBER & STAFF NUMBERS \\
\hline Dispensary & 24 & 35 \\
Hospitals & 2 & 34 \\
TOTAL & 26 & 69 \\
\hline
\end{tabular}

The study tool was pretested in Lamuria Area of Laikipia East Sub-County.

This area was chosen because it has similar social Economic features as Laikipia North Sub-County.

A sum of 25 care givers of children aged 0 to 23 months interviewed for the pre-test phase. The pilot phase was to test the accuracy and clarity of the questionnaires and modifications were effected on questions found to be ambiguous.

Data validity and reliability were achieved through pre-testing of the data collection instruments before the actual study in a population that was similar to the one to be used in the actual study, in addition to training and close supervision of the research assistants by the principal investigator and through data cleaning.

\subsection{Data Collection and Analysis Procedure}

Structured questionnaires were administered by pre-trained research assistants in house to house visits to care givers of children aged 0 to 23 months.

The study tool was pretested in Lamuria Area of Laikipia East Sub-County.

This area was chosen because it has similar social Economic features as Laikipia North Sub-County.

A sum of 25 care givers of children aged 0 to 23 months interviewed for the pre-test phase. The pilot phase was to test the accuracy and clarity of the questionnaires and modifications were effected on questions found to be ambiguous.

Data validity and reliability were achieved through pre-testing of the data collection instruments before the actual study in a population that was similar to the one to be used in the actual study, in addition to training and close supervision of the research assistants by the principal investigator and through data cleaning.

Each homestead that had a birth in the last 2 years was selected and accorded a number, this was written down, folded and placed in a cistern and mixed up. Interviewers randomly and blindly selected the folded pieces of paper from the cistern, equal to the sample size per sub location. The selected homesteads were then visited by the interviewers.

Mother Child booklet records were recorded by the assistants in the questionnaire. In situations where the Mother Child Booklet, Vaccination status were determined by maternal or care giver Recall.

Health facility staff questionnaires were administered to check on availability of Vaccines, equipment, vaccine administration commodities, enough room for Vaccination, reporting tools and mother child booklets in health facilities. 
The principal researcher coordinated and ensured that the data collection process was properly administered. Research assistants were carefully selected and trained on how to administer the questionnaires.

Questionnaires were coded to ensure anonymity, confidentiality and security of personal information concerning research participants. This data was accessed by the researcher only. The raw questionnaires were archived and stored by the researcher at Nanyuki Teaching and Referral Hospital data archiving store. Archiving of the questionnaires will be for 6 years as per the Ministry of Health Archiving policy.

Data was entered, coded and cleaned in the SPSS version 24. Statistical analysis of the data was performed using SPSS version 24 (IBM-SPSS Inc. Chicago, USA).

Proportions, frequency and percentages were calculated. Differences in proportions between groups were compared using the Chi-square tests.

CHI square and student T-test calculation was used to assess factors influencing uptake of vaccines in the sub-county separately.

Findings were presented in form of frequency distribution tables, pie charts and bar graphs.

\section{Results}

\subsection{Response Rate}

A total of 332 care givers of Children aged 0 to 23 months who live in Laikipia North Sub County participated in the study This represents a maximum (100\%) response rate.

\subsection{Demographic Characteristics of Participants}

\subsubsection{Demographic Characteristics of Respondents}

Results showed that all (100\%) the caregivers in the study were female. They further show that majority (61\%) of the caregivers were aged between 21 years and 30 years with the mean age being 26 years. Slightly above half (53\%) of the respondents had not acquired any formal education. Majority (86\%) of the caregivers were married with half (50\%) being in polygamous marriages and $36 \%$ in monogamous marriages. $90 \%$ of the care givers were mothers to children aged between 0 - 23 months while $7 \%$ were guardians and 3\% siblings. About $58 \%$ of the respondents were Christians with $30 \%$ being protestants and $28 \%$ being Catholics, $34 \%$ had no religion while $8 \%$ confessed to the African traditional religion (Table 3).

\subsubsection{Demographic Characteristics of Children}

Slightly above half (57\%) of the children were boys while $43 \%$ were girls. Slightly less than half (48\%) of the children were aged 7 months and below while $34 \%$ were aged between 8 and 15 months. The mean age of the children was 9 months, with a standard deviation of (Table 4). 
3.2.3. Relationship between Demographic Factors and Vaccine Coverage Results in Table 5 show that marital status of the caregiver $(\mathrm{p}<0.001)$, level of education $(\mathrm{p}<0.001)$ and religion $(\mathrm{p}<0.001)$ significantly influence vaccine coverage of newly introduced vaccines.

Table 3. Demographic characteristics of respondents.

\begin{tabular}{|c|c|c|c|}
\hline Characteristic & Category & Frequency & Percentage \\
\hline Gender & Female & 332 & 100 \\
\hline \multirow[t]{6}{*}{ Age (Years) } & $10-20$ & 19 & 6 \\
\hline & $21-30$ & 203 & 61 \\
\hline & $31-40$ & 94 & 28 \\
\hline & $41-50$ & 16 & 5 \\
\hline & Mean age & 26 & \\
\hline & Standard Deviation & 7.1 & \\
\hline \multirow[t]{4}{*}{ Level of education } & None & 177 & 53 \\
\hline & Primary & 61 & 18 \\
\hline & Secondary & 62 & 19 \\
\hline & Post-secondary & 32 & 10 \\
\hline \multirow[t]{3}{*}{ Marital status } & Married monogamous & 119 & 36 \\
\hline & Married Polygamous & 166 & 50 \\
\hline & Single/separated/divorced/widowed & 47 & 14 \\
\hline \multirow[t]{3}{*}{ Relationship } & Mother & 299 & 90 \\
\hline & Guardian & 23 & 7 \\
\hline & Siblings & 10 & 3 \\
\hline \multirow[t]{4}{*}{ Religion } & None & 114 & 34 \\
\hline & Christian (catholic) & 92 & 28 \\
\hline & Christian (protestant) & 100 & 30 \\
\hline & African traditional religion & 26 & 8 \\
\hline
\end{tabular}

Table 4. Demographic characteristics of index children.

\begin{tabular}{cccc}
\hline Characteristic & Category & Frequency & Percentage \\
\hline Gender & Male & 190 & 57 \\
& Female & 142 & 43 \\
Age (months) & $0-7$ & 159 & 48 \\
& $8-15$ & 114 & 34 \\
& $16-23$ & 59 & 18 \\
& Mean age & 9 & \\
\hline
\end{tabular}


Table 5. Relationship between demographic factors and vaccine coverage.

\begin{tabular}{cccc}
\hline & $\chi^{2}$ & $\mathrm{df}$ & P-Value \\
\hline Gender & N/A & N/A & N/A \\
Age & 3.686 & 3 & 0.297 \\
Marital status & 24.113 & 2 & $<0.001^{\star * *}$ \\
Level of education & 20.555 & 3 & $<0.001^{\star * *}$ \\
Religion & 21.980 & 3 & $<0.001^{\star * *}$ \\
\hline
\end{tabular}

\subsection{Vaccine Coverage for Various Vaccine Antigens}

\subsubsection{Vaccination of Children}

Slightly above half (59\%) of the caregivers in the study indicated that their child had been vaccinated with the newly introduced vaccines (Figure 1 ). This was further confirmed through the postnatal mother child booklets that the caregivers presented to the interviewers.

\subsubsection{Information on Newly Introduced Vaccines}

Slightly (59\%) above half of the respondents were given information by the health workers on newly introduced vaccines, the rest had no information that there were newly introduced vaccines (Figure 2).

However, on being asked to identify the newly introduced vaccines, only $43 \%$ of the respondents could identify the three newly introduced vaccines while $57 \%$ did not know (Figure 3).

\subsection{Knowledge of Recommended Schedule/Doses of the Newly Introduced Vaccines}

Knowledge of the individual Vaccines and the frequency of doses that a child should receive amongst the respondent showed that $52.7 \%$ knew that Rota should be received twice, 47.3 knew Pneumococcal should be at 3 doses and $50.3 \%$ knew that IPV should only be given once to their children.

\subsection{Type of Vaccine Given to Child}

Majority (62\%) of the caregivers had their children given rotavirus vaccine while $61 \%$ had their children given Pneumococcal vaccine. Slightly above half (52\%) of the caregivers indicated that their children were given IPV vaccine (Figure 4).

\subsection{Number of Newly Introduced Vaccines Doses Children Received}

Out of the children who had been vaccinated, majority (85\%) of them had received two doses of rotavirus vaccine thus completed the schedule for this vaccine. $78 \%$ had received 3 doses of pneumococcal vaccine as per the schedule while all the children who were vaccinated with Inactivated Polio Vaccine were given the recommended one dose (Table 6). 


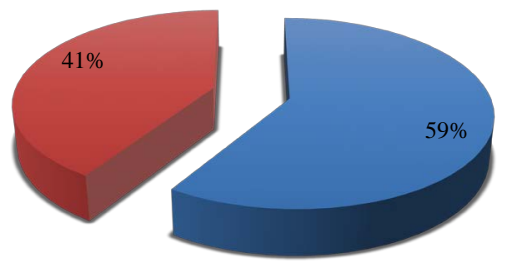

- Yes No

Figure 1. Vaccination of children.

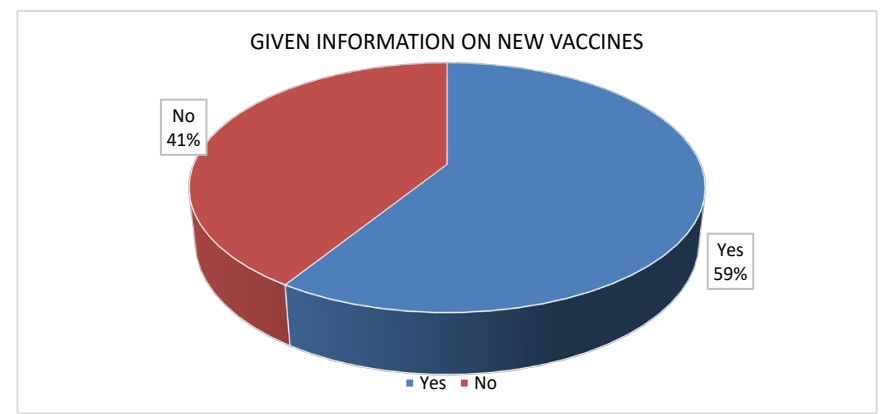

Figure 2. Caregiver given information about NIVs.

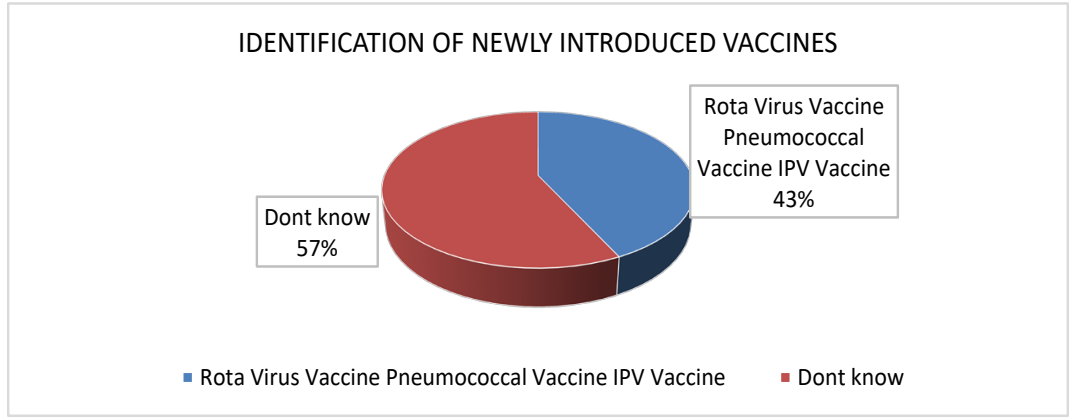

Figure 3. Identification of NIVs.

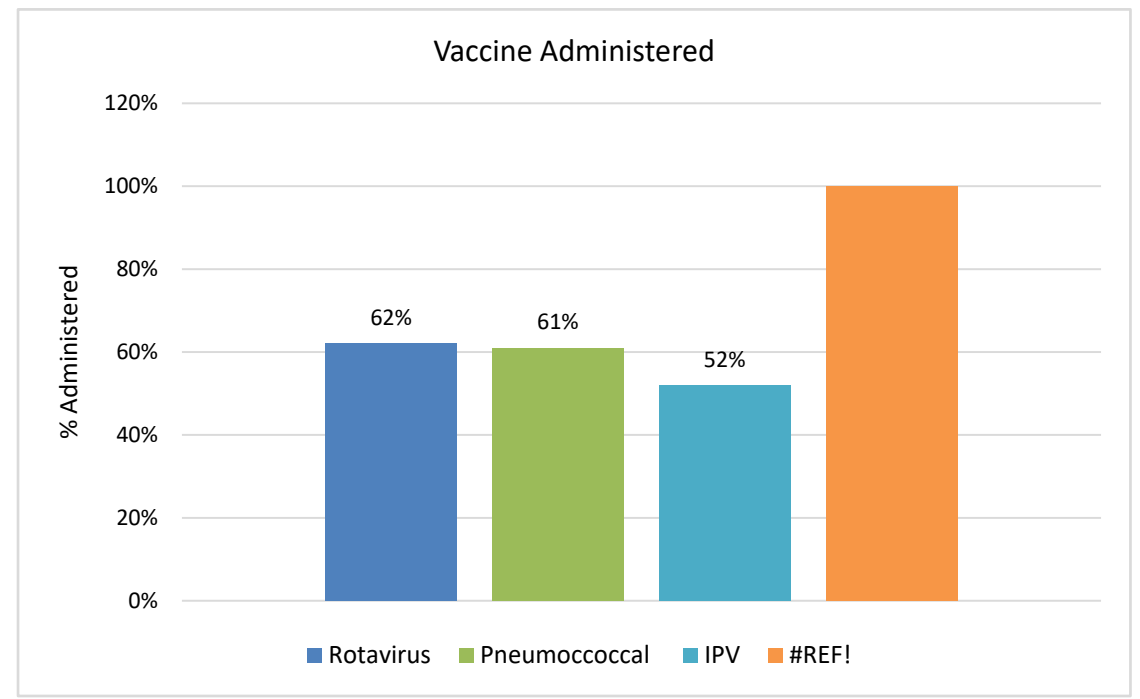

Figure 4. Type of Vaccine given to child. 
Table 6. Number of times child vaccinated.

\begin{tabular}{cccc}
\hline Vaccine & Dosage & Frequency & Percentage \\
\hline Rotavirus vaccine & 1 & 30 & 15 \\
& 2 & 176 & 85 \\
PCV & Total & 206 & 100 \\
& 1 & 27 & 13 \\
& 2 & 18 & 9 \\
& 3 & 157 & 78 \\
IPV & Total & 202 & 100 \\
& 1 & 170 & 100 \\
\hline
\end{tabular}

\subsection{Reasons for Not Having Child Vaccinated}

$43.7 \%$ of the mothers cited the long distances to the health facility as the main reason why they didn't take their child for Vaccination, this was followed by Migration at $24.6 \%$, lack of money at $9.9 \%$, not knowing the need at $7.7 \%$, closing of the facility $5.6 \%$ and Facility Not Vaccinating 5.6\% and Husband refusing at $2.8 \%$ (Figure 5 ).

\subsection{Social-Cultural Factors}

\subsubsection{Social-Cultural Beliefs and Practices}

$58 \%$ of the care givers indicated that they need permission from their Husbands for them to take their children for vaccination. $43 \%$ needed permission from their mother-in-laws to vaccinate their children. Similarly, $74 \%$ of the caregivers agreed that migration with their animals makes it hard to vaccinate children while $60 \%$ believed that vaccination at a very young age was harmful to children.

However, $70 \%$ of the caregivers believed that their communities encouraged vaccination same as their religion at $75 \%$.

$61 \%$ of the caregivers did not believe that girls should be vaccinated but as opposed to boys. Similarly, 44\%indicated that vaccination makes girls infertile (Table 7).

\subsubsection{Relationship between Social-Cultural Factors and Vaccine Coverage for NIVs}

Findings in Table 8 show that permission from my mother-in-law $(p=0.003)$, belief that vaccination makes girls infertile $(p=0.046)$ and belief that vaccination at a very young age can harm the child $(p=0.021)$, Migration with Animals makes it hard to vaccinate children $(\mathrm{p}=0.033)$, I need permission from my husband to have the Child Immunized $(p=0.038)$ significantly influence uptake of newly introduced vaccine among the caregivers. 


\subsection{Social-Economic Factors}

\subsubsection{Occupation}

$54.8 \%$ of the Guardians Were Nomadic Cattle keepers, with $18.4 \%$ being peasant farmers and $16.3 \%$ unemployed. $64.5 \%$ of the Children fathers were unemployed while $31.9 \%$ were self-employed (Table 9 ).

\subsubsection{Breadwinner in the Family}

Majority (76\%) of the caregivers in the study indicated that it was the spouse who was the breadwinner in the family while in $19 \%$ of the cases, it was the caregiver herself who was the breadwinner (Figure 6).

Table 7. Social-Cultural factors.

\begin{tabular}{|c|c|c|c|c|c|}
\hline & 1 & 2 & 3 & 4 & 5 \\
\hline $\begin{array}{l}\text { My community discourages vaccination of } \\
\text { children }\end{array}$ & $8 \%$ & $6 \%$ & $16 \%$ & $56 \%$ & $14 \%$ \\
\hline My religion is against vaccination of children & $8 \%$ & $6 \%$ & $11 \%$ & $43 \%$ & $32 \%$ \\
\hline $\begin{array}{l}\text { I need permission from my husband to have the } \\
\text { child immunized. }\end{array}$ & $13 \%$ & $25 \%$ & $20 \%$ & $24 \%$ & $18 \%$ \\
\hline $\begin{array}{l}\text { I need permission from my mother-in-law to have } \\
\text { the child immunized }\end{array}$ & $8 \%$ & $16 \%$ & $19 \%$ & $42 \%$ & $15 \%$ \\
\hline Girls should be vaccinated but not boys & $5 \%$ & $8 \%$ & $26 \%$ & $34 \%$ & $27 \%$ \\
\hline Vaccination makes girls infertile & $6 \%$ & $8 \%$ & $30 \%$ & $29 \%$ & $27 \%$ \\
\hline $\begin{array}{l}\text { Vaccination at a very young age can harm the } \\
\text { child }\end{array}$ & $17 \%$ & $25 \%$ & $28 \%$ & $20 \%$ & $10 \%$ \\
\hline $\begin{array}{l}\text { Migration with our animals makes it hard to } \\
\text { vaccinate children }\end{array}$ & $62 \%$ & $12 \%$ & $4 \%$ & $12 \%$ & $10 \%$ \\
\hline
\end{tabular}

Table 8. Relationship between Social-Cultural factors and vaccine coverage for NIVs.

\begin{tabular}{llll}
\hline & $\chi^{2}$ & df & P-Value \\
\hline $\begin{array}{l}\text { My community discourages vaccination of } \\
\text { children }\end{array}$ & 3.091 & 4 & 0.543 \\
My religion is against vaccination of children & 4.165 & 4 & 0.384 \\
$\begin{array}{l}\text { I need permission from my husband to have the child } \\
\text { immunized. }\end{array}$ & 6.963 & 4 & $0.038^{*}$ \\
$\begin{array}{l}\text { I need permission from my mother-in-law to have the } \\
\text { child immunized }\end{array}$ & 16.417 & 4 & $0.003^{*}$ \\
$\begin{array}{l}\text { Girls should be vaccinated but not boys } \\
\text { Vaccination makes girls infertile }\end{array}$ & 6.221 & 4 & 0.183 \\
$\begin{array}{l}\text { Vaccination at a very young age can harm the child } \\
\text { Migration with our animals makes it hard to vaccinate } \\
\text { children }\end{array}$ & 9.696 & 4 & $0.046^{*}$ \\
\hline
\end{tabular}

${ }^{*}=0.05,{ }^{* *}=0.001,{ }^{* *}=0.0001$. 
Table 9. Occupation.

\begin{tabular}{cccc}
\hline & Occupation Status & Frequency & Percentage \\
\hline Respondent & None & 54 & 16.3 \\
& Nomadic Cattle Farmers & 182 & 54.8 \\
& Peasant farmers & 61 & 18.4 \\
& Sand harvester & 20 & 6.0 \\
Business & 15 & 4.5 \\
Epouse & Employed & 12 & 3.6 \\
& Self employed & 106 & 31.9 \\
& Unemployed & 214 & 64.5 \\
\hline
\end{tabular}

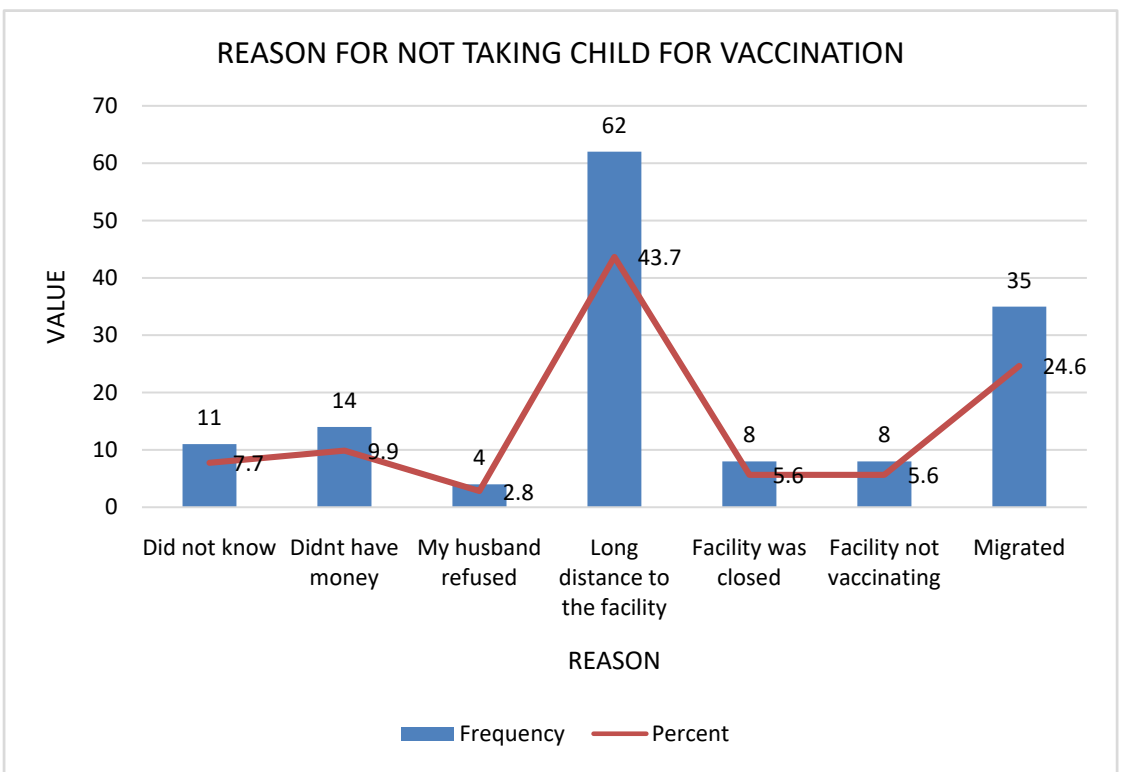

Figure 5. Reason for not having child vaccinated.

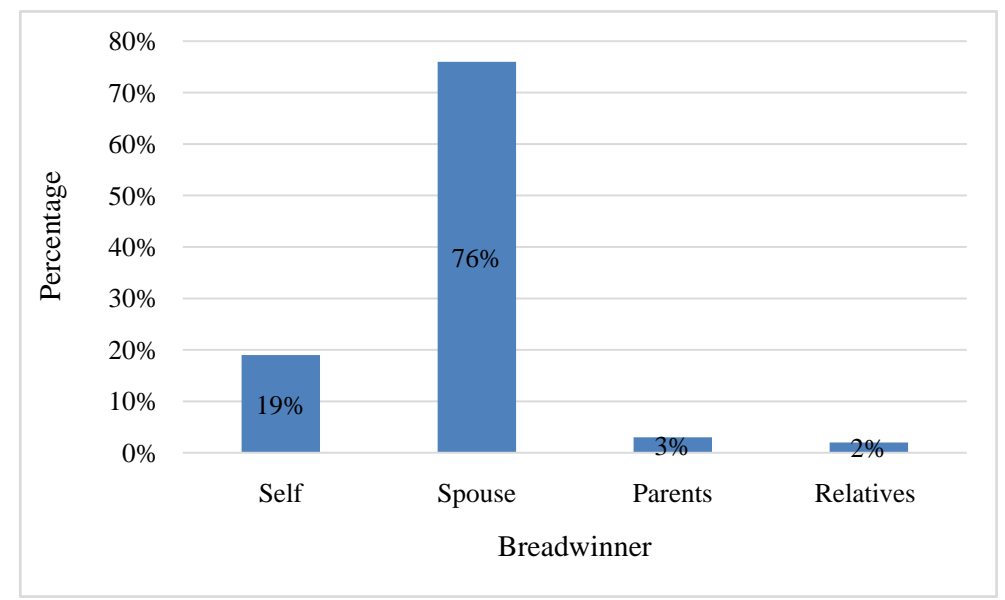

Figure 6. Breadwinner in the family. 


\subsubsection{Average Household Income}

Results in Table 10 show that slightly above half (57\%) of the respondents had an average monthly income of between KES 2501 and KES 5000. 16\% of the households, the average income was between KES 1001 and KES 2500 while 17\% of households, had an average income of between KES 5001 and KES 7500.

\subsubsection{Means of Transport to Health Facility}

Majority (73\%) of caregivers walked to their nearest health facility while $24 \%$ used bodaboda (Motor Cycles) (Figure 7).

\subsubsection{Relationship between Social-Economic Factors and Vaccine Coverage}

Results in Table 11 show that occupation of the caregiver $(p=0.044)$, the breadwinner in the family ( $\mathrm{p}=0.025$ ) and the means of transport used to go to the facility $(p=0.007)$ and average Household income $(p=0.033)$ were significantly related to uptake of vaccination.

\subsection{Health Facility Factors}

\subsubsection{Type of Facility}

The vast majority ( $88 \%$ ) of facilities in the study were public (Figure 8).

\subsubsection{HCWs Providing Vaccination Services}

In the vast majority (89\%) of facilities, it is nurses who were providing Vaccination services (Figure 9).

Table 10. Average household income.

\begin{tabular}{ccc}
\hline Income (KES) & Frequency & Percentage \\
\hline KES 1000 & 8 & 3 \\
KES 1001 - KES 2500 & 53 & 16 \\
KES 2501 - KES 5000 & 190 & 57 \\
KES 5001 - KES 7500 & 54 & 17 \\
KES 7501 - KES 10,000 & 12 & 3 \\
$>$ KES 10,001 & 15 & 4 \\
Total & 332 & 100 \\
\hline
\end{tabular}

Table 11. Relationship between Social-Economic factors and vaccine coverage.

\begin{tabular}{cccc}
\hline & $\chi^{2}$ & df & $\mathrm{p}$ \\
Occupation & 9.811 & 4 & $0.044^{* * *}$ \\
Employment status of spouse & 2.837 & 3 & 0.417 \\
Breadwinner & 11.188 & 4 & $0.025^{* * *}$ \\
Average household income & 7.871 & 5 & $0.033^{* * *}$ \\
Means of transport used & 12.160 & 3 & $0.007^{\star * *}$ \\
\hline
\end{tabular}

${ }^{*}=0.05,{ }^{* *}=0.0011^{* *}=0.0001$. 


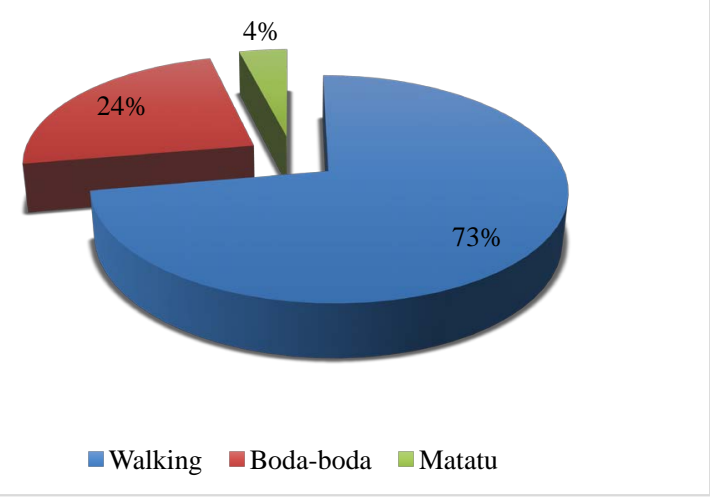

Figure 7. Means of transport to health facility.

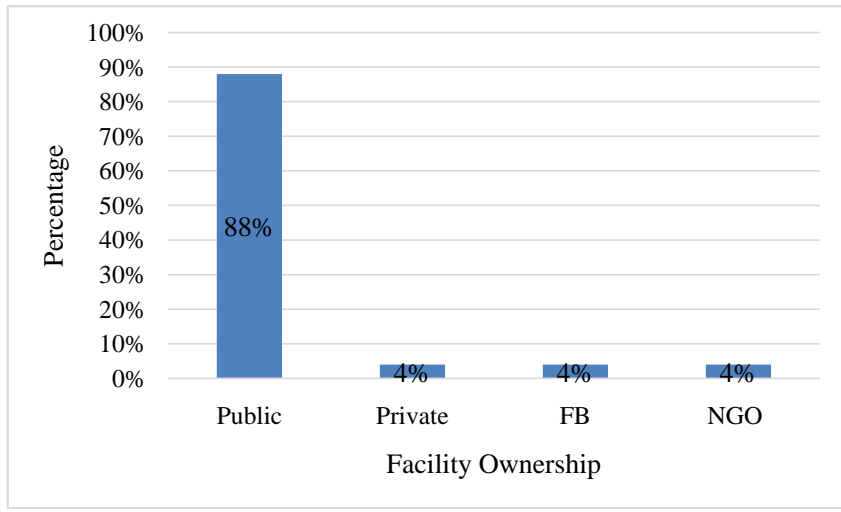

Figure 8. Type of facility.

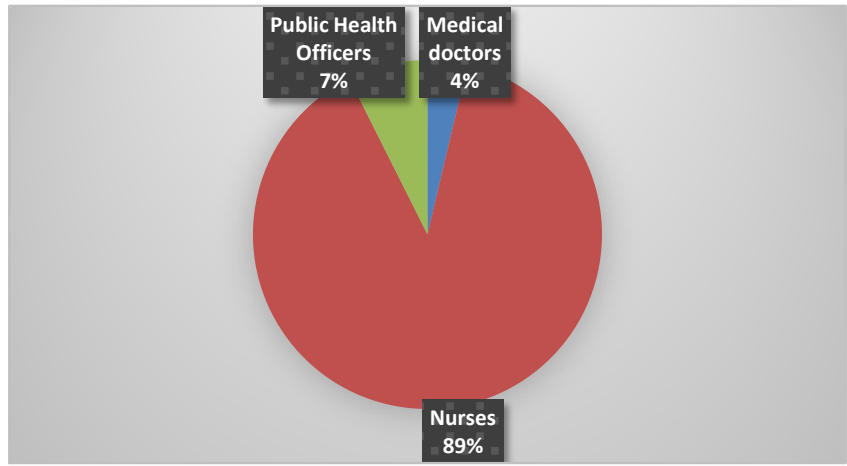

Figure 9. HCWs providing vaccination services.

\subsubsection{Presence of Equipment and Services for Vaccination}

Findings in Table 12 show that majority (92\%) of facilities had been working vaccine refrigerators, $85 \%$ had vaccine carriers, $88 \%$ had cold frozen ice packs and $58 \%$ had up-to-date inventory for vaccines and medicines. Results show that majority (88\%) of facilities had first-in first-out stock controls for vaccines to minimize drug expiration, $69 \%$ had all vaccines stored under conducive conditions to maintain quality of items, $92 \%$ of the facilities offered preventive child and maternal services and $81 \%$ had mobile immunization outreach clinics carried out. Results show that majority (65\%) of the facilities did not have cold 
boxes, $62 \%$ did not have a reliable power source while $58 \%$ lacked availability of $100 \%$ of vaccines on the day of the facility visit. The results further show that no defaulters of the newly introduced vaccines were encountered in $81 \%$ of the facilities.

\subsubsection{HCWs Work Experience in the Health Facility}

69 health workers participated in the study. Majority (65\%) of the health workers in the study had a worked between 1 and 5 years while $27 \%$ had worked less than one year in the health facilities they were in (Figure 10).

\subsubsection{HCWs Received EPI Training}

Majority (69\%) of the health workers in the study indicated that they had not received any in service KEPI training post college (Figure 11).

Table 12. Presence of equipment and services for immunization.

\begin{tabular}{|c|c|c|}
\hline & Yes & No \\
\hline Vaccine Refrigerator & $92 \%$ & $8 \%$ \\
\hline Vaccine Cold boxes & $35 \%$ & $65 \%$ \\
\hline Vaccine carriers & $85 \%$ & $15 \%$ \\
\hline Cold Frozen Ice packs & $88 \%$ & $12 \%$ \\
\hline $\begin{array}{l}\text { Power source which is available consistently when services are } \\
\text { being offered }\end{array}$ & $38 \%$ & $62 \%$ \\
\hline $100 \%$ of offered vaccines available the day of the facility visit & $42 \%$ & $58 \%$ \\
\hline Up-to-date inventory for vaccines and medicines & $58 \%$ & $42 \%$ \\
\hline $\begin{array}{l}\text { First-in first-out stock storage for vaccines to minimize drug } \\
\text { expiration }\end{array}$ & $88 \%$ & $12 \%$ \\
\hline $\begin{array}{l}\text { All vaccines stored under conditions conducive to maintain } \\
\text { quality of items }\end{array}$ & $69 \%$ & $31 \%$ \\
\hline Facility offers preventive child and maternal services & $92 \%$ & $8 \%$ \\
\hline Mobile immunization outreach clinics carried out & $81 \%$ & $19 \%$ \\
\hline Defaulters of the newly introduced vaccines encountered & $19 \%$ & $81 \%$ \\
\hline
\end{tabular}

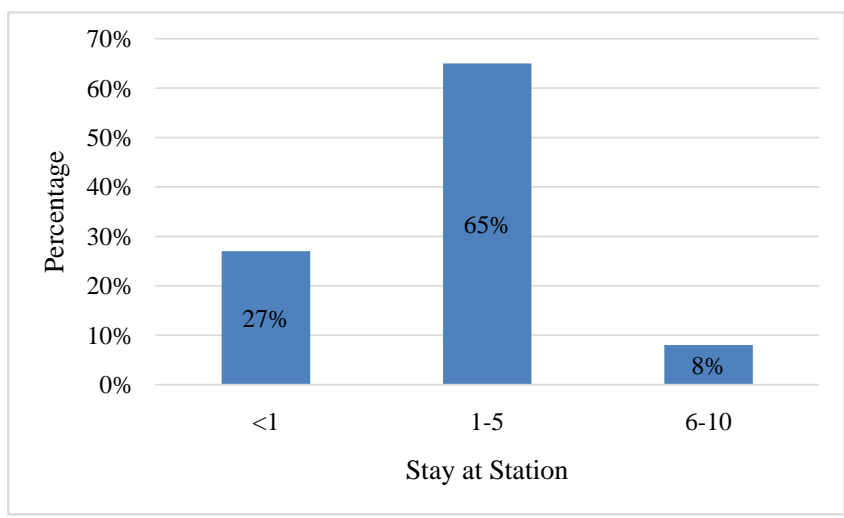

Figure 10. HCWs work experience at the health facility. 


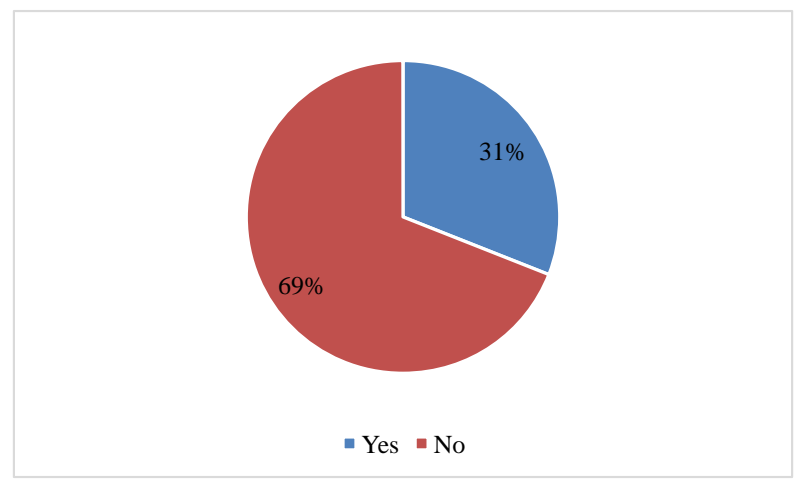

Figure 11. HCW received KEPI training.

\subsubsection{Period Which HCWs Received KEPI Training}

Half (50\%) of the respondents received KEPI training between 6 and 10 years ago while $36.4 \%$ received KEPI training between 1 and 5 years prior to the study (Table 13).

\subsubsection{Health Care Workers Training on Newly Introduced Vaccines}

Half $(50 \%)$ of the health workers in the study had received training on vaccines while half (50\%) did not. Those who did not participated indicated that they were not selected (Figure 12).

\subsubsection{Reasons for Not Being Trained on EPI and NIVs}

$68.1 \%$ of the health workers who had not been trained indicated that they were never selected for the trainings while $17 \%$ indicated there were no funds to over the training (Table 14).

\subsubsection{Knowledge of Population to Immunize with NIVs}

The vast majority $(88 \%)$ of the respondents indicated that they were aware of the number and age of children whom they were supposed to vaccinate with newly introduced vaccines (Figure 13).

\subsubsection{Facility Vaccination Coverage}

Majority (71\%) of the health workers in the study indicated that their facility had a coverage of between 41 and 80 while 17\% indicated below $40 \%$ and $12 \%$ between 81 and 100 (Figure 14).

\subsubsection{Factors Contributing to Low Coverage}

Fifty-eight percent (58\%) of the respondents reported that low coverage experienced in their facilities was attributed to lack of equipment like vaccine fridges, and cold boxes, Commodities and materials like vaccine syringes and vaccine stock outs, reporting tools and Vaccine monitoring charts. Majority (65\%) reported that staff levels, their practices, training, availability and Motivation highly contributed to low coverage. Table 15 shows that service delivery timing, Community participation and vaccine demand creation marginally contributed to low coverage according to $50 \%$ and $47 \%$ respectively but $38 \%$ and $27 \%$ disagreed. Aspects related to Data collection and reporting were mentioned to fairly 
contribute to low coverage at $42 \%$, though $43 \%$ of the respondents reported that Monitoring and Evaluation and supportive supervision acted to some extent to low coverage.

Table 13. Period which HCWs received KEPI training.

\begin{tabular}{ccc}
\hline Period & Frequency & Percentage \\
\hline$<1$ year ago & 3 & 13.6 \\
$1-5$ years ago & 8 & 36.4 \\
$6-10$ years ago & 11 & 50 \\
Total & 22 & 100 \\
\hline
\end{tabular}

Table 14. Reasons for not being trained on EPI and NIVs.

\begin{tabular}{rcc}
\hline REASON & FREQUENCY & PERCENTAGE \\
\hline I was not selected & 32 & 68.1 \\
I was not interested & 3 & 6.4 \\
No funds & 8 & 17.0 \\
Time was not available & 2 & 4.3 \\
No need for training & 2 & 4.3 \\
\hline
\end{tabular}

Table 15. Factors contributing to low coverage.

\begin{tabular}{cccccc}
\hline & Very high & High & Fair & Low & Very low \\
\hline Supply of Equipment's, commodities and materials & 12 & 46 & 19 & 19 & 4 \\
Staff & 27 & 38 & 0 & 15 & 19 \\
Service delivery timing & 19 & 31 & 12 & 19 & 19 \\
Community participation and demand creation & 12 & 35 & 27 & 12 & 15 \\
Data collection reporting & 8 & 27 & 42 & 19 & 4 \\
M \& E and supportive supervision & 8 & 35 & 0 & 31 & 27 \\
\hline
\end{tabular}

Key: $\mathrm{n}=69$ (Figure in Percentage).

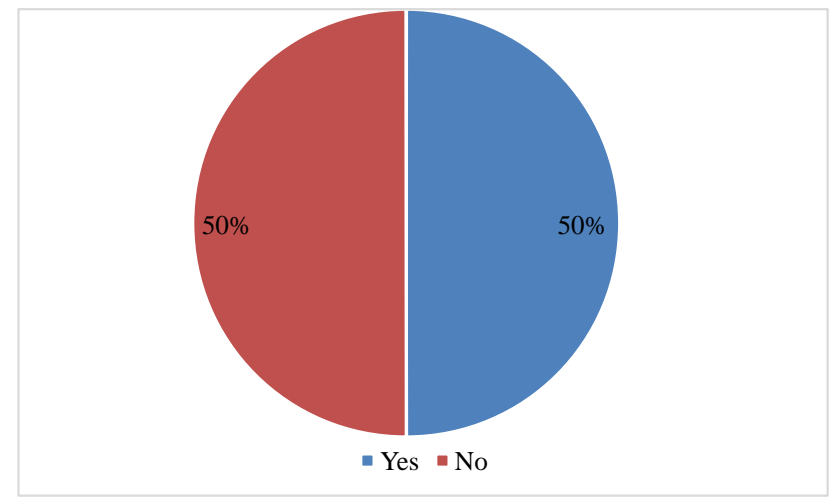

Figure 12. Health care workers received training on vaccines. 


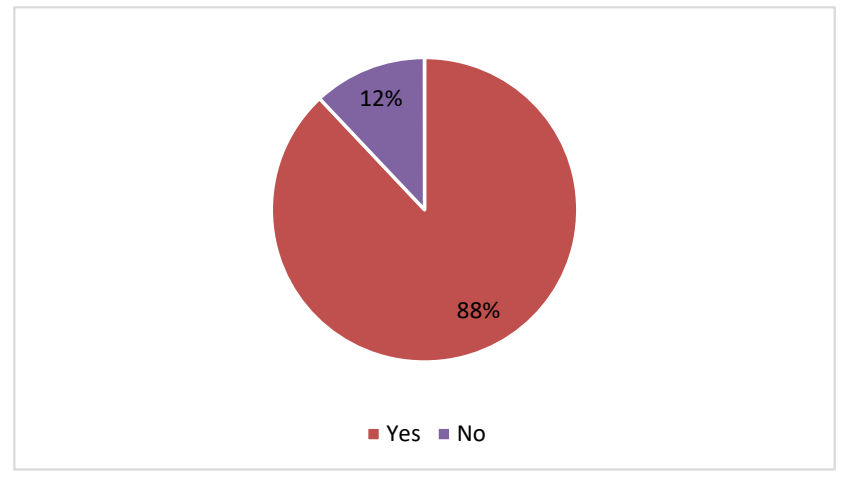

Figure 13. Knowledge of population to vaccinate with NIVs.

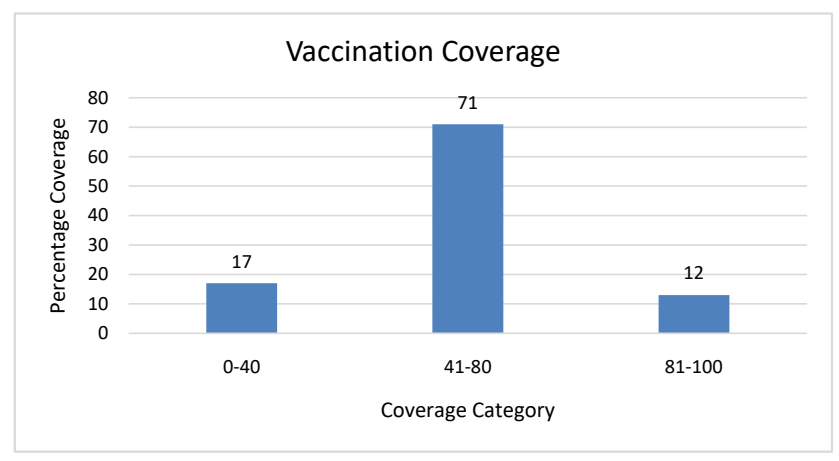

Figure 14. Facility coverage.

\subsubsection{Recommendations to Increase Vaccine Coverage for NIVs}

Majority (81\%) of the respondents recommended availability of vaccination materials and vaccines to avoid stock outs would be a measure to increase coverage on the newly introduced vaccines. Similarly, the respondents recommended daily immunization (84\%), defaulter tracing (65\%), and daily health education sessions to mothers who visit health facilities (54\%).

Equally identified were proper documentation, accurate timely reporting, review and utilization of data to make informed decisions both at 58 percent would increase vaccine coverage especially for newly introduced vaccines (Table 16).

\subsubsection{Challenges Facing New Vaccines}

Among the major challenges reported by respondents include interruption of power to sustain cold chain (42\%), lack of motivation to staff (37.7\%) and periodic stock outs of the newly introduced Vaccines (14.5\%) (Table 17).

\subsubsection{Factors Influencing Uptake of Vaccination}

Slightly less than half (46.4\%) cited nomadism while $26.1 \%$ indicated long distance to facility as factors preventing mothers from bringing their children for vaccination (Table 18).

\subsubsection{Relationship between Health Facility Factors and Vaccine Coverage}

None of the health system factors under investigation was found to significantly relate to uptake of vaccination (Table 19). 


\section{Discussion}

\subsection{Vaccine Coverage for Various Vaccine Antigens}

The study sought to determine the vaccine coverage for various vaccine antigens in Laikipia North sub-county. The study found that slightly above half (59\%) of the caregivers in the study indicated that their children had been vaccinated with the newly introduced vaccines. Majority (61\%) of the caregivers had their children given rotavirus vaccine while an equal number $(61 \%)$ had their children given Pneumococcal vaccine. Slightly above half (52\%) of the caregivers indicated that their children were given IPV vaccine. Slightly above half (53\%) of the children who were given rotavirus vaccine were given 2 dosages. The findings

Table 16. Recommendations to increase vaccine coverage for NIVs.

\begin{tabular}{lccccc}
\hline & Very high & High & Fair & Low & Very low \\
\hline Ensure no material and vaccine stock outs & 46 & 35 & 15 & 0 & 4 \\
Daily immunization & 46 & 38 & 8 & 4 & 4 \\
Defaulter tracing & 38 & 27 & 8 & 12 & 15 \\
$\begin{array}{c}\text { Daily health talks to create demand for the service } \\
\text { Proper documentation and accurate timely reporting }\end{array}$ & 23 & 31 & 19 & 23 & 4 \\
Review and use data to make informed decisions & 27 & 31 & 23 & 15 & 4 \\
\hline
\end{tabular}

KEY: Percentage $(n=69)$.

Table 17. Challenges facing new vaccines.

\begin{tabular}{ccc}
\hline Reason & Frequency & Percentage \\
\hline Periodic lack of vaccines & 10 & 14.5 \\
Interrupted power to sustain cold chain & 29 & 32 \\
Lack of motivation to staff & 26 & 5.8 \\
Gas for facility & 4 & 100 \\
Total & 69 & \\
\hline
\end{tabular}

Table 18. Factors influencing uptake of vaccination.

\begin{tabular}{ccc} 
Reason & Frequency & Percentage \\
\hline $\begin{array}{c}\text { Distance to the health facility } \\
\text { Too many vaccines at one }\end{array}$ & 18 & 26.1 \\
Education level of caregiver & 6 & 11.6 \\
Nomadism & 8 & 46.4 \\
Lack of daily immunization & 32 & 7.2 \\
Total & 5 & 100 \\
\hline
\end{tabular}


Table 19. Relationship between health system factors and vaccine coverage.

\begin{tabular}{|c|c|c|c|}
\hline & $\chi^{2}$ & $\mathrm{df}$ & $\mathrm{p}$ \\
\hline Type of Facility & 2.719 & 4 & 0.257 \\
\hline Caliber of HCWs Providing Immunization Services & 0.791 & 4 & 0.673 \\
\hline Presence of Refrigerator & 0.074 & 4 & 0.964 \\
\hline Presence of Cold boxes & 1.060 & 4 & 0.600 \\
\hline Presence of Vaccine carriers & 1.37 & 4 & 0.934 \\
\hline Presence of Ice packs & 0.057 & 4 & 0.972 \\
\hline Presence of reliable Power source & 0.786 & 4 & 0.695 \\
\hline Presence of $100 \%$ of offered vaccines & 0.300 & 4 & 0.861 \\
\hline Up-to-date inventory for vaccines and medicines & 0.300 & 4 & 0.861 \\
\hline First-in first-out stock storage for vaccines & 0.134 & 4 & 0.935 \\
\hline Proper storage of vaccines & 0.132 & 4 & 0.936 \\
\hline Availability of preventive child and maternal services & 0.074 & 4 & 0.964 \\
\hline Availability of Mobile immunization outreach clinics & 0.035 & 4 & 0.983 \\
\hline Defaulters of the newly introduced vaccines encountered & 0.035 & 4 & 0.983 \\
\hline HCWs Working Experience & 1.625 & 4 & 0.444 \\
\hline HCWs KEPI training & 0.304 & 4 & 0.859 \\
\hline $\begin{array}{l}\text { Causes related to the supply of Equipment's, commodities and } \\
\text { materials }\end{array}$ & 2.555 & 5 & 0.768 \\
\hline Causes related to staffing & 3.609 & 4 & 0.462 \\
\hline Causes related to service delivery timing & 2.417 & 5 & 0.789 \\
\hline Causes related to community participation and demand creation & 3.0983 & 5 & 0.686 \\
\hline Causes related to data collection reporting & 3.686 & 5 & 0.595 \\
\hline M\&E and supportive supervision & 2.232 & 4 & 0.693 \\
\hline
\end{tabular}

show that slightly less than half (47\%) of the children who were given PCV received 3 doses. Results also show that half (50\%) of the children who received IPV got 1 dose. The findings therefore show that vaccine coverage for the newly introduced vaccines was low. This finding is consistent with findings of the KDHS 2014 that put Laikipia north's immunization coverage at 56\%, similarly, studies by [8] [9] [10] and [11] who found that uptake of vaccination among the population living in topographically similar arid and semi-arid and rural regions of Western Kenya, Papua New Guinea, Myanmar had low vaccine coverages.

\subsection{Social-Cultural Factors Associated with Vaccine Uptake}

The study sought to determine the social-cultural factors influencing the uptake of newly introduced vaccines among children aged less than one year in Laikipia North Sub County.

The study found that marital status of the caregiver $(\mathrm{p}<0.001)$ significantly 
influences uptake of newly introduced vaccines. Additionally, permission from the Husband $(\mathrm{p}=0.038)$ and permission from the Mother in law also significantly influence administration with NIVs. These finds agree with studies in Bushenyi District of Uganda that found that although Mothers are the primary care givers of children, fathers often make decisions about participation in government programs and their objections have often been identified as one of the barriers to their children's participation in vaccination programs [12].

Care givers level of education $(\mathrm{p}<0.001)$ also significantly influenced the uptake of newly introduced vaccines, with majority (53\%) of the care givers having no formal education. These results are in agreement with a study conducted in sub-Saharan Africa which demonstrated that women's literacy was positively associated with increased healthcare access and usage [13]. Similarly, in Ethiopia Vaccine studies identified and recommended that mothers be educated on the importance of family planning, breast feeding and immunization programs in efforts to reduce child morbidity and mortality [14].

Religion $(\mathrm{p}<0.001)$ significantly influenced vaccine coverage for newly introduced vaccines, with $58 \%$ of the respondents being Christians and $75 \%$ of the respondents disagreeing that their religion is against vaccination of children. The findings disagree with those who found that differences in religious affiliation were associated with differences in immunization rates [15].

Majority (61\%) disagreed that girls should be vaccinated but not boys. Similarly, 56\% disagreed that vaccination makes girls infertile. These finds disagreed with [16] and [17] who observed significant child gender-based differences and preferences between boys' and girls' immunization coverages and access to services.

Results also show that $70 \%$ of the community did not believe that their community discourages Vaccination of children, $40 \%$ disagreed that vaccination at a very young age can harm the child however $46 \%$ of mothers who did not vaccinate their children selected long distance to the health facility as their major reason closely followed at $26 \%$ and majority $(74 \%)$ of the caregivers agreed that migration with their animals makes it hard to vaccinate children. The findings agree with a study conducted in Delhi, India among rural-urban migrant mothers with a child aged up to 2 years found immunization coverage rates were lower among migrant children and even lower among recent migrants (11). It also agrees with a study conducted in 2012 among children aged between 12 and 59 months, that found that travel time to vaccine providers in health posts appeared to be a barrier to the delivery of infant vaccines in a remote Ethiopian community [18].

\subsection{Social-Economic Factors Associated with Vaccine Uptake}

The study assessed Social-Economic factors influencing the uptake of newly introduced vaccines among children aged less than 23 months in Laikipia North Sub County. The study found that majority of the caregivers in the study were 
either Nomadic farmers $(54.8 \%)$ or Peasant farmers $(18.4 \%)$. The results also show that $64 \%$ of the spouses of caregivers were unemployed. However, this is attributable to the understanding by the community that employment is only associated with salary or wages as opposed to farming. These results agree with studies in India that showed that a person's habitat, caste and occupation determined awareness and acceptance of vaccination services. The same study also showed that distinct tribal regions with distinct socio economic activities like pastoralism or arable farming showed differences in demand for public health services [19].

Majority (76\%) of the caregivers in the study indicated that it was the spouse who was the breadwinner in the family. These results agree with Nuwaha et al. in Uganda who observed that although mothers are primary caregivers of children, fathers often make decisions about their participation in government programs and their objections have often been identified as one of the barriers to their children participation in vaccination programs.

Results also show that slightly above half (57\%) of the respondents had an average monthly income of between KES 2501 and KES 5000. Majority (73\%) of caregivers walked to their nearest health facility while $24 \%$ used bodaboda.

Occupation of the caregiver $(\mathrm{p}=0.044)$, the breadwinner in the family $(\mathrm{p}=$ $0.025)$ and the means of transport used to go to the facility $(\mathrm{p}=0.007)$ and average household income ( $\mathrm{p}=0.033$ ) were significantly related to uptake of vaccination.

These findings agree with the findings of Godi et al. (2008) which showed that although majority of mothers were aware of vaccination, their reception of vaccination services was mainly determined by their habitat, caste, and occupation. Such results are also consistent with those of Legesse et al. 2015 who showed that children from household whose average monthly income was greater than 1000 ETB or 52USD were three times more likely to be fully vaccinated than whose income is low.

The findings of the present study are also consistent with studies in Kilifi that showed that vaccination coverages are usually reduced with each additional kilometer walked to the health facility in Kilifi [20].

The results of this study were also consistent with those of (7) who in studies conducted in rural western Kenya and Papua New Guinea showed that long distance to health facilities significantly reduced the use of health services by the population.

\subsection{Health Facility Factors Influencing Vaccine Uptake}

The study also determined health facility factors influencing uptake of newly introduced vaccines among children aged less than 23 months in Laikipia North Sub County.

The study found that (92\%) of facilities had vaccine refrigerators, $85 \%$ had vaccine carriers, $88 \%$ had ice packs and $58 \%$ had up-to-date inventory for vac- 
cines and medicines. Health workers also reported that low vaccine coverage was attributable to causes related to supply of equipment and materials (52\%) and that improving vaccine coverage can be attained by ensuring no materials or vaccine stock outs (81\%).

These findings agree with a UNICEF report of 2011 that stated that to achieve better immunization coverage health infrastructure, need to be in place at primary level facilities in order to avoid events of missed opportunities. Infrastructure in this case was focused on vaccine storage, transport and availability of vaccines at the depot.

However, the findings disagree with studies that found that a major effect of new vaccines are the additional cold chain requirements and increasing complexity to handle vaccines with different requirements in terms of temperature stability; some of the new vaccines require significant expansions of cold chain capacity [21]. This is because the extra vaccines in Laikipia North did not require any additional cold Chain facilities or infrastructure.

A major shortfall was that Majority (69\%) of the health workers in the study indicated that they had not received KEPI training. For those who have been trained $88 \%$ had their training happening beyond a year ago. With only $12 \%$ of the health workers indicating that their level of education can influence vaccine uptake. These findings agree with studies that found that a very small percentage (25\%) of district health management team members had undergone KEPI training [22]. This might explain the low vaccination in Laikipia North, in view of Mangrio et al. 2008 healthcare workers' knowledge and practices are influential factors in preventing vaccine failures. Adequate knowledge and practices in the cold chain system are important to keep potency of vaccines and effectiveness of immunization.

The results of the present study indicated that $73 \%, 77 \%$ and $81 \%$ of the health workers reported that daily health talk sessions when caregivers visit the health facility created greater demand for newly introduced vaccines, Proper documentation and accurate timely reporting and review and use of data to make informed decisions highly influenced the uptake of newly introduced vaccines. This was consistent with Grooms et al. 2008 who stated that the introduction of NIVs which had also meant higher investments led to a heightened awareness of the need for general information systems that support decision-making and enabled monitoring and surveillance at Central, Provincial and District levels [23]. Integrated data collection was indicated to facilitate feedback to the lower levels. Good immunization tracking systems can assist the delivery of catch-up vaccines.

However, none of the health system factors under investigation was found to significantly relate to uptake of vaccination. These findings are in disagreement with Brenzel et al. who in studies conducted in rural western Kenya and Papua New Guinea showed that long distance to health facilities significantly reduced the use of health services by the population. The finding is in disagreement with Ayaya et al. who found evidence that the training associated with the introduc- 
tion of NIVs-especially on-the-job training-tends to be associated with improved vaccine coverage and better overall quality of service. The findings are also in disagreement with Djibuti et al. who found evidence that there were significant improvements in the extent and quality of the monitoring and supervisory efforts during vaccine campaigns with well-functioning health facilities.

\section{Conclusion and Recommendations}

\subsection{Conclusion}

The study concludes that vaccine coverage for various newly introduced vaccine antigens in Laikipia North Sub-County is low. Although a fair number of children had been vaccinated at least once, a big proportion (41\%) of caregivers did not produce their children for vaccination at the recommended age. This reduces the effectiveness of the vaccines since they are only effective when given to higher percentage of children, at the recommended age and with the required number of dosages.

Social-cultural factors are associated with the uptake of newly introduced vaccines among children aged less than 23 months in Laikipia North Sub-County. Specifically, lack of women's autonomy and mythical beliefs reduce vaccination coverage. Marital status, education level and religion of the care givers, need for permission from their husband and mother-in-law, those who believed that vaccination makes girls infertile and those who believed that vaccination at a very young age can harm the child were found to have not had their children vaccinated.

Social-Economic factors were associated with the uptake of newly introduced vaccines among children aged less than one year in Laikipia North Sub-County. Specifically, occupation of the caregiver, the breadwinner in the family and the means of transport used to go to the facility were significantly related to uptake of vaccination. Caregivers who were unemployed, whose spouses were unemployed and who had an average household income of less than KES 5000 were found to be most likely not to have vaccinated their children. The lack of adequate income means that caregivers are preoccupied with getting basic needs like food and only take the child to hospital when he/she is sick. Unemployed caregivers also depend on their spouses for money who may not necessarily value vaccination.

Health facility factors were found not to influence the uptake of newly introduced vaccines among children aged less than 23 months in Laikipia North Sub County. However, some gaps were noted in the health system, such as lack of some equipment and training of health workers. These factors did not significantly influence uptake of newly introduced vaccines in the study area.

\subsection{Recommendations}

Initiate Mobile vaccination and outreach clinics in the study area with necessary cold chain equipment to enhance uptake of vaccines. 
Enhance and promote health education campaigns on the need for vaccination to the target groups in the population. Daily Health education sessions in the Department of MCH with emphasis on vaccination. Village vaccination and health meetings to reduce the influence of husbands' and mothers-in-law on child vaccination.

Disseminate research findings to policy makers and County Government with the hope that socio economic ventures can be initiated in the study area to improve education and reduce poverty levels.

County government to equip health facilities with necessary cold chain equipment and vaccines for effective vaccination services.

Regular training and updating of health workers on newly introduced vaccines should be done by the County Government.

\section{Definition of Terms}

Infant: A child whose age is less than 23 Months.

Cohort: A group of people sharing a common temporal demographic experience who are observed through time.

Demographic Surveillance System (DSS): A set of field and computing operations to handle the longitudinal follow-up of well-defined entities or primary subjects (individuals, households, and residential units) and all related demographic and health outcomes within a clearly circumscribed geographic area.

Demographic Surveillance Area (DSA): The catchment area of a Health and Demographic Surveillance System.

Household: A social group of one or more individual members eating from the same pot. They are usually but not always related biologically or by blood.

Vaccine: A vaccine is a biological preparation that improves immunity to a particular disease. A vaccine typically contains an agent that resembles a diseasecausing microorganism. The agent stimulates the body's immune system to recognize the agent as foreign, destroy it, and "remember" it, so that the immune system can more easily recognize and destroy any of these microorganisms that it later encounters (WHO definition).

Vaccination Uptake: Number of routine doses of a vaccine administered to a child. In this study, the vaccines considered are all the routine immunization vaccines administered in Kenya.

Factor: An aspect of personal behaviour or lifestyle, environmental exposure, or inborn or inherited characteristic which, on the basis of epidemiologic evidence, is known to be associated with a health-related condition considered important to prevent (WHO definition). In this study, the risk factors considered are the socioeconomic and demographic characteristics of infants and their mothers.

Socioeconomic Status (SES): A classification of the social group of an individual based on his/her assets, type of residence and utilities.

\section{Conflicts of Interest}

The authors declare no conflicts of interest regarding the publication of this paper. 


\section{References}

[1] Akumu, A.O., English, M., Scott, J.A. and Griffiths, U.K. (2007) Economic Evaluation of Delivering Haemophilus influenzae Type b Vaccine in Routine Immunization Services in Kenya. Bulletin of the World Health Organization, 85, 511-518. https://doi.org/10.2471/BLT.06.034686

[2] World Health Organization (2009) State of the World's Vaccines and Immunization. 3rd Edition, World Health Organization, Geneva, 1-13.

[3] Bhandari, P., Shrestha, S.S. and Ghimire, D.J. (2007) Sociocultural and Geographical Disparities in Child Immunization in Nepal. Asia-Pacific Population Journal, 22, 43-64. https://doi.org/10.18356/1e441780-en

[4] Kiros, G.E. and White, M.J. (2004) Migration, Community Context, and Child Immunization in Ethiopia. Social Science \& Medicine, 59, 2603-2616.

https://doi.org/10.1016/j.socscimed.2004.04.009

[5] World Health Organization, Department of Vaccines and Biologicals (2005) Vaccine Introduction Guideline, Adding a Vaccine to a National Immunization Programme: Decision and Implementation. World Health Organization, Geneva, 25-36.

[6] World Health Organization, Department of Vaccines and Biologicals (2005) Vaccine Introduction Guideline, Adding a Vaccine to a National Immunization Programme: Decision and Implementation. World Health Organization, Geneva, 8.

[7] World Health Organization (2002) State of the World's Vaccines and Immunizations. World Health Organization, Geneva, 11-16.

[8] Brenzel, L., Wolfson, L.J., Fox-Rushby, J., Miller, M. and Halsey, N.A. (2006) Vaccine-Preventable Diseases. In: Jamison, D.T., Breman, J.G., Measham, A.R., Alleyne, G., Claeson, M., Evans, D.B., Eds., Disease Control Priorities in Developing Countries, 2nd Edition, The World Bank, Washington DC, 389-412. https://doi.org/10.1596/978-0-8213-6179-5/Chpt-20

[9] Buor, D. (2003) Analysing the Primacy of Distance in the Utilization of Health Services in the Ahafo-Ano South District, Ghana. The International Journal of Health Planning and Management, 18, 293-311. https://doi.org/10.1002/hpm.729

[10] Canavati, S., Plugge, E., Suwanjatuporn, S., Sombatrungjaroen, S. and Nosten, F. (2011) Barriers to Immunization among Children of Migrant Workers from Myanmar Living in Tak Province, Thailand. Bulletin of the World Health Organization, 89, 528-531. https://doi.org/10.2471/BLT.10.084244

[11] Kusuma, Y.S., Kumari, R., Pandav, C.S. and Gupta, S.K. (2010) Migration and Immunization: Determinants of Childhood Immunization Uptake among Socioeconomically 72 Disadvantaged Migrants in Delhi, India. Tropical Medicine \& International Health, 15, 1326-1332. https://doi.org/10.1111/j.1365-3156.2010.02628.x

[12] Nuwaha, F., Mulindwa, G., Kabwongyera, E. and Barenzi, J. (2000) Causes of Low Attendance at National Immunization Days for Polio Eradication in Bushenyidistrict, Uganda. Tropical Medicine \& International Health, 5, 364-369.

https://doi.org/10.1046/j.1365-3156.2000.00560.x

[13] McTavish, S., Moore, S., Harper, S. and Lynch, J. (2010) National Female Literacy, Individual Socio-Economic Status, and Maternal Health Care Use in Sub-Saharan Africa. Social Science \& Medicine, 71, 1958-1963. https://doi.org/10.1016/j.socscimed.2010.09.007

[14] Girma, B. and Berhane, Y. (2011) Children Who Were Vaccinated, Breast Fed and from Low Parity Mothers Live Longer: A Community Based Case-Control Study in 
Jimma, Ethiopia. BMC Public Health, 11, Article No. 197. https://doi.org/10.1186/1471-2458-11-197

[15] Antai, D. (2009) Faith and Child Survival: The Role of Religion in Childhood Immunization in Nigeria. Journal of Biosocial Science, 41, 57-76. https://doi.org/10.1017/S0021932008002861

[16] Singh, A. (2012) Gender Based Within-Household Inequality in Childhood Immunization in India: Changes over Time and across Regions. PLOS ONE, 7, e35045. https://doi.org/10.1371/journal.pone.0035045

[17] Pande, R.P. (2003) Selective Gender Differences in Childhood Nutrition and Immunization in Rural India: The Role of Siblings. Demography, 40, 395-418. https://doi.org/10.1353/dem.2003.0029

[18] Okwaraji, Y.B., Mulholland, K., Schellenberg, J.R., Andarge, G., Admassu, M. and Edmond, K.M. (2012) The Association between Travel Time to Health Facilities and Childhood Vaccine Coverage in Rural Ethiopia. A Community Based Cross Sectional Study. BMC Public Health, 12, Article No. 476. https://doi.org/10.1186/1471-2458-12-476

[19] Godi, et al. (2008) Immunization Coverage in Tribal and Rural Areas of Visakhapatnum District of Andhra Pradesh. India Journal of Public Health, 16, 389-397. https://doi.org/10.1007/s10389-008-0186-9

[20] Ndiritu, M., Cowgill, K.D., et al. (2006) Immunization Coverage and Risk Factors for Failure to Immunize within the Expanded Programme on Immunization in Kenya after Introduction of New Haemophilus influenzae Type b and Hepatitis b Virus Antigens. BMC Public Health, 6, Article No. 132. https://doi.org/10.1186/1471-2458-6-132

[21] Griffiths, U.K., Korczak, V.S., et al. (2009) Incremental System Costs of Introducing Combined DTwP-Hepatitis B-Hib Vaccine into National Immunization Services in Ethiopia. Vaccine, 27, 1426-1432. https://doi.org/10.1016/j.vaccine.2008.12.037

[22] Ayaya, S.O., Liechty, E., et al. (2007) Training Needs for Mid-Level Managers and Immunisation Coverage in Western Kenya. East African Medical Journal, 84, 342-352. https://doi.org/10.4314/eamj.v84i7.9590

[23] Groom, H., Bhatt, A., et al. (2008) Temporary Vaccine Recommendations and Provider Compliance: A Survey of Pediatric Practices during the 2003-2004 Pneumococcal Conjugate Vaccine Shortage. Pediatrics, 122, e835-e840.

https://doi.org/10.1542/peds.2008-1092 


\section{Appendix 1. Questionnaire for Caregivers}

Dear respondents

\section{RE: RESEARCH QUESTIONNAIRE}

I am a student at the Meru University of Science and Technology doing Master of Science Degree in Epidemiology. I am currently conducting a study on factors Influencing uptake of newly introduced vaccines among children aged less than 23 months year in Laikipia County. I kindly request you to take part of your time to complete this questionnaire. Your honest feedback will be of highest importance in the course of my academic research. This information will not be used to serve any other purpose other than for academic purpose.

Section A: Respondents' socio-demographic characteristics

1) What is your gender?

Male [ ] Female [ ]

2) How old are you?

$<20$ years [ ] $21-30$ years [ ] $31-40$ years [ ] $41-50$ years [ ] $>50$ years [ ]

3) What is your highest level of education?

None [ ] Primary (incomplete) [ ] Primary (complete) [ ] Secondary (incomplete) [ ] Secondary (complete) [ ] College certificate [ ] College diploma [ ] Degree [ ] Post-graduate degree [ ]

4) What is your marital status?

Single [ ] Married Polygamous [ ] married monogamous [ ] Divorced/separated [ ] Widowed [ ]

5) what is your relationship with this child?

Mother [ ] Guardian [ ] Sibling [ ]

What is your religion?

Christian (catholic) [ ] Christian (protestants) [ ] Muslim [ ] African Traditional Religion [ ] others [ ]

What is the gender of your child?

Male [ ] Female [ ]

How old is this child?

0 - 7 months [ ] 8 - 15 months [ ] $16-23$ months [ ]

Section B: Vaccine Coverage for Various Vaccine Antigens

9) Has this child been vaccinated? (Ask for the Mother Child Booklet)

Yes [ ] No [ ]

If yes, were you told about the new vaccine? Yes [ ] No [ ]

If No, go to Question 12.

10) Which are the newly introduced vaccines? (CHECK THE Mother Child Booklet)

Rota virus vaccine Pneumococcal vaccine IPV vaccine [ ]

BCG vaccine OPV vaccine DPT + HepB - Hib [ ]

Measles Vaccine Yellow fever Vaccine Other Vaccine [ ]

11) Tick where appropriate according to mother child book check what the child has received? 


\begin{tabular}{ccccccc}
\hline & \multicolumn{3}{c}{ Frequency } & \multicolumn{3}{c}{ Age in weeks timing } \\
\cline { 2 - 7 } Vaccine & 1 & 2 & 3 & 6 wks. & 10 wks. & 14 wks. \\
\hline Vaccine & & & & & & \\
Rota virus vaccine & & & & & & \\
Pneumococcal vaccine & & & & & \\
IPV vaccine
\end{tabular}

What made you not take/get your child vaccinated with newly introduced vaccines?

Did not know about vaccination [ ] Did not have money [ ] My husband refused [ ] the health facility is along distance from where I live [ ] the health facility was closed [ ] my nearest facility does not vaccinate [ ] we migrated at the time [ ]

\section{Section C: Social-Cultural and Economic Factors}

13) Indicate your response by ticking on the appropriate box:

$1=$ Strongly Agree $2=$ Agree $3=$ Uncertain $4=$ Disagree $5=$ Strongly Disagree

$\begin{array}{lllll}1 & 2 & 3 & 4 & 5\end{array}$

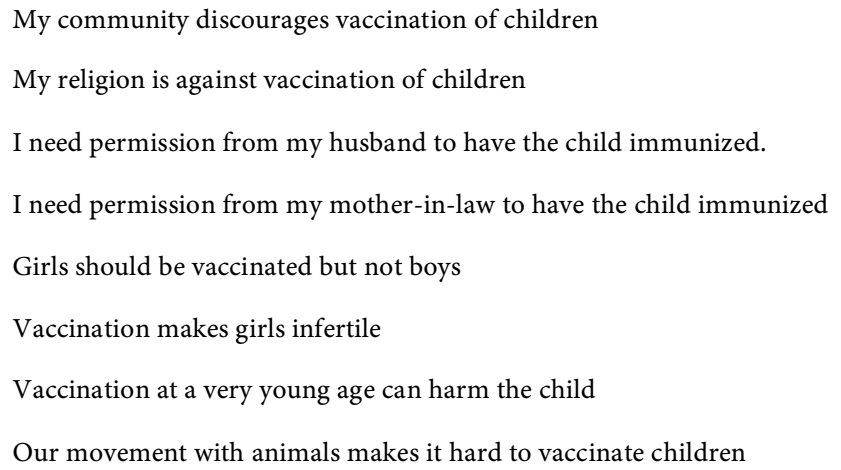

\section{Social Economic Factors}

14) a) What is your occupation?

Peasant farmer [ ] Nomadic Cattle farmer [ ] Sand Harvester [ ] businessman/lady [ ] None [ ]

b) What is the occupation of the father of your child?

Formal Employed [ ] Self-employed [ ] Not employed [ ]

15) Who is the breadwinner in the family?

Myself [ ] my spouse [ ] my sibling [ ] my parents [ ] Relatives [ ] Grandparents [ ]

16) What is your average household income per month?

<KES 1000 [ ] KES 1001 - KES 2500 [ ] KES 2501 - KES 5000 [ ] KES 5001 - KES 7500 [ ] KES 7501 - KES 10,000 [ ] >KES 10,001 [ ]

17) How do you travel to the clinic?

Walking [ ] Boda-boda [ ] Matatu [ ] Taxi [ ] 


\section{Appendix 2. Questionnaire for Health Workers}

The purpose of this questionnaire is to enable me study the Factors influencing Uptake of newly introduced vaccines among Infants in Laikipia North Sub County Laikipia County. Please respond by ticking along your preferred answer. To maintain anonymity and confidentiality DO NOT indicate your name or that of your facility.

This facility is owned by?

Public [ ] Private [ ] FBO [ ] NGO [ ]

In this facility Vaccination services are provided by which cadre?

Nurses [ ] Public Health Officers [ ] Medical Doctors

Does your facility have the following equipment?

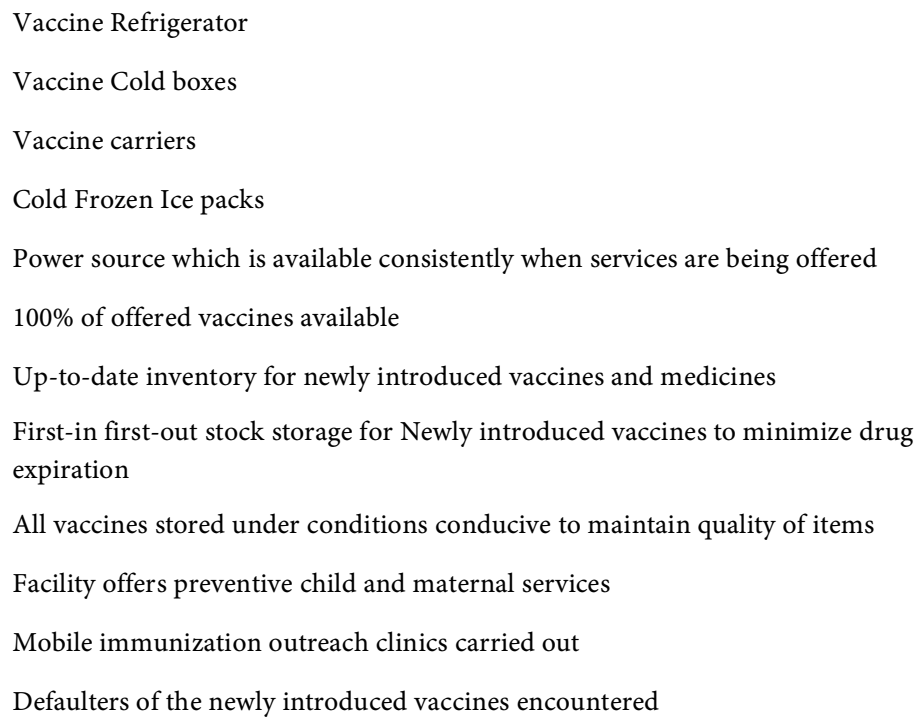

How long have you been working at the current health facility?

Less than 1 year [ ] 1 to 5 years [ ] 6 to 10 years [ ]

5) Have you attended any KEPI training? (If no skip to Q 8)

Yes [ ] No [ ]

6) If yes above, when?

$<1$ year ago [ ] 1 - 5 years ago [ ] 6 - 10 years ago [ ]

7) Did you receive any training on NIVs (PCV-10, Rota virus and IPV vaccines)?

Yes [ ] No [ ]

8) If no, what were the reasons for having not received any training?

I was not selected [ ]

I was not interested [ ]

No funds [ ]

Time was not available [ ]

No need for training [ ] 
Others (specify)

N/A [ ]

\section{Section D: Health Facility Factors}

9) Does the facility know the number and age of children's they are supposed to Vaccinate with NIVs? Yes [ ] No [ ]

If yes what is facility coverage?

0 - 40 [ ] $41-80$ [ ] $81-100$ [ ]

10) Please grade the following the factors according to the level of contribution that they have to low coverage of newly introduced vaccines

$1=$ Very high $2=$ High $3=$ Fair $4=$ Low $5=$ Very low

$\begin{array}{lllll}1 & 2 & 3 & 4 & 5\end{array}$

Causes related to the supply of Equipment's, commodities and materials ( Fridges, Vaccines, Syringes, Carriers etc.

Causes related to staffing ( training, Motivation, Availability,

Numbers)

Causes related to service delivery timing ( daily, Weekly, Monthly)

Causes related to community participation and demand creation

( health Education, Outreaches)

Causes related to data collection reporting

M\&E and supportive supervision

11) What can the facility do to increase coverage on the newly introduced vaccines? Ratings

$1=$ Very high $2=$ High $3=$ Fair $4=$ Low $5=$ Very low

$\begin{array}{lllll}1 & 2 & 3 & 4 & 5\end{array}$

Ensure no material and vaccine stock outs

Daily immunization

Defaulter tracing

Daily health talks to create demand for the service

Proper documentation and accurate timely reporting

Review and use data to make informed decisions

12) In your opinion, what vaccination challenges are related to the new vaccines at this health facility?

Periodic lack of vaccines [ ]

Interrupted power to sustain cold chain [ ]

Lack of Gas for facility cold chain [ ]

Lack of motivation to staff [ ]

8) In your opinion, what factors prevent mothers from bringing their children for vaccination? 
Distance to the health facility [ ]

Fear of side effects [ ]

Too many vaccines at one [ ]

Education level of caregiver [ ]

Nomadism [ ]

\section{List of Abbreviations and Acronyms}

DSA: Demographic Surveillance Area

DSS: Demographic Surveillance System

EPI: Expanded Programme on Immunization

KDHS: Kenya Demographic Health Survey

KEMSA: Kenya Medical Supplies Agency

KEPI: Kenya Expanded Programme on Immunization

LMICs: Low- and Middle-Income Countries

MDG: Millennium Development Goals

NIVs: Newly Introduced Vaccines

MOH: Ministry of Health

SDGs: Sustainable Development Goals

SES: Socioeconomic Status

SPSS: Statistical Package for Social Sciences

UNICEF: United Nations International Children's Emergency Fund

WHO: World Health Organization 